\title{
Possibility of leg muscle hypertrophy by ambulation in older adults: a brief review
}

This article was published in the following Dove Press journal:

Clinical Interventions in Aging

28 March 2013

Number of times this article has been viewed

\author{
Hayao Ozaki' \\ Jeremy P Loenneke ${ }^{2}$ \\ Robert S Thiebaud ${ }^{2}$ \\ Joel M Stager ${ }^{3}$ \\ Takashi $\mathrm{Abe}^{3}$ \\ 'Juntendo University, Inzai, Chiba, \\ Japan; ${ }^{2}$ Department of Health \\ and Exercise Science, University \\ of Oklahoma, Norman, OK, USA; \\ ${ }^{3}$ Department of Kinesiology, Indiana \\ University, Bloomington, IN, USA
}

Correspondence: Takashi Abe Department of Kinesiology, Indiana University, 1025 East 7th Street, Room 104, Bloomington, IN 47405, USA

$\mathrm{Tel}+\mathrm{I} 8128567163$

$\mathrm{Fax}+\mathrm{I} 8128553193$

Email t12abe@gmail.com

\begin{abstract}
It is known that ambulatory exercises such as brisk walking and jogging are potent stimuli for improving aerobic capacity, but it is less understood whether ambulatory exercise can increase leg muscle size and function. The purpose of this brief review is to discuss whether or not ambulatory exercise elicits leg muscle hypertrophy in older adults. Daily ambulatory activity with moderate ( $>3$ metabolic equivalents [METs], which is defined as the ratio of the work metabolic rate to the resting metabolic rate) intensity estimated by accelerometer is positively correlated with lower body muscle size and function in older adults. Although there is conflicting data on the effects of short-term training, it is possible that relatively long periods of walking, jogging, or intermittent running for over half a year can increase leg muscle size among older adults. In addition, slow-walk training with a combination of leg muscle blood flow restriction elicits muscle hypertrophy only in the blood flow restricted leg muscles. Competitive marathon running and regular high intensity distance running in young and middle-aged adults may not produce leg muscle hypertrophy due to insufficient recovery from the damaging running bout, although there have been no studies that have investigated the effects of running on leg muscle morphology in older subjects. It is clear that skeletal muscle hypertrophy can occur independently of exercise mode and load.
\end{abstract}

Keywords: aerobic exercise, muscle mass, aging, strength, sarcopenia

\section{Introduction}

Brisk walking and jogging are recommended for improving maximal oxygen uptake $\left(\mathrm{VO}_{2} \mathrm{max}\right)$ in older men and women. ${ }^{1-3}$ Elite race walkers have high $\mathrm{VO}_{2}$ max values, ${ }^{4,5}$ which are similar to elite long distance and marathon runners. ${ }^{4}$ Although endurance exercise is generally not prescribed for increasing muscle mass, some cross-sectional studies have observed greater muscle fiber cross-sectional areas (CSA) in the leg muscles of distance runners than that of untrained subjects. ${ }^{6,7}$ Although the previous studies observed change in muscle fiber size resulting from running, the whole muscle volume or CSA has not been investigated. Thus, it is unclear whether the greater muscle fiber CSA in distance runners is due to running or if it is influenced by genetic factors. ${ }^{8}$ In addition, with cross-sectional studies it is difficult to separate the possibility that the athletes, in many cases, also performed resistance exercise. Therefore, the effects of endurance exercise on muscle hypertrophy and strength gain are not well known.

In general, a training intensity of more than $60 \%$ of one's concentric one repetition maximum (1RM) is commonly considered the minimum intensity required to achieve muscle hypertrophy. ${ }^{9}$ In recent years, however, it has been established that myofibrillar protein synthesis is maximally stimulated following acute work matched 
resistance exercise at $60 \%$ of $1 \mathrm{RM}$, and that increasing the external load provided no additional stimulation in the synthesis rate. ${ }^{10}$ Nevertheless, when resistance exercise is not matched for work and is taken to volitional fatigue, even lower exercise intensities appear capable of maximizing the synthetic response. To illustrate, low intensity knee extension exercise at $30 \%$ of $1 \mathrm{RM}$ has been demonstrated to increase myofibrillar protein synthesis at rates that are similar to those observed with higher intensity resistance exercise (90\% 1RM). However, the lower intensity group to failure resulted in a more sustained synthetic response. ${ }^{11}$ Recently, these findings have been extended to demonstrate that when low intensity ( $30 \%$ of $1 \mathrm{RM}$ ) resistance exercise to failure is performed repeatedly, comparable increases in muscle hypertrophy (whole muscle and fiber level) are observed between low and high intensities. ${ }^{12,13}$ Additionally, very low intensity exercise training such as walking (approximately $10 \%$ of maximum voluntary contraction) combined with blood flow restriction (BFR) to the exercising muscles can elicit muscle hypertrophy and strength gain in young and older adults. ${ }^{14,15}$ These increases in muscle size and strength have also been previously observed with aerobic exercise in older women without BFR, although the intensity used was approximately $60 \%-80 \%$ of the heart rate reserve. ${ }^{16}$ These results suggest that high external loads are not a prerequisite for increasing muscle protein synthesis, and ultimately muscle hypertrophy. The exercise intensity to lower limb muscles during brisk walking and jogging is approximately $\sim 30 \%$ of maximum voluntary contraction. ${ }^{17,18}$ Thus, it is possible that ambulation exercise with a sufficient workload may induce muscle hypertrophy and strength gain. Therefore, the purpose of this brief review is to discuss whether or not brisk walking and jogging/running elicits muscle hypertrophy and strength gain in older adults.

\section{Daily physical activity and leg muscle size and function}

During the last decade, only a few studies have reported the relationship between accelerometer (or pedometer) determined physical activity and skeletal muscle size in middle-aged and older populations. For example, Bassey et $\mathrm{al}^{19}$ found that triceps surae muscle strength was significantly and positively correlated $(\mathrm{r}=0.30, P<0.05)$ with recorded amounts of daily walking when averaged over 7 consecutive days in men aged $>65$ years. Scott et $\mathrm{al}^{20}$ reported that ambulatory activity averaged over 7 consecutive days is positively associated with both leg strength and muscle quality in women aged 50-79 years.
The associations between ambulatory activity and both leg strength and muscle quality were nonsignificant in men. ${ }^{20}$ In addition, the authors reported that there was no significant association between ambulatory activity and dual energy X-ray absorptiometry (DXA) estimated leg lean tissue mass. On the other hand, Park et $\mathrm{al}^{21}$ reported a significant positive correlation between DXA estimated appendicular lean tissue mass and year averaged duration of physical activity at $>3$ metabolic equivalents (METs) in women $(\mathrm{r}=0.38$, $P<0.05)$ and men $(\mathrm{r}=0.28, P<0.05)$ aged $65-84$ years. $^{21}$ Since DXA assesses the sum of lean tissue mass, which includes the anterior and posterior upper leg and lower leg, site specific muscle mass cannot be determined by this method. Recently, Abe et $\mathrm{al}^{22}$ reported that accelerometer determined ambulatory activity, especially moderate and vigorous intensities ( $>3$ METs), is positively correlated with the tibialis anterior $(\mathrm{r}=0.34, P<0.05)$, as well as by the triceps surae muscle thickness $(\mathrm{r}=0.41, P<0.01)$, suggesting that $>3$ METs of physical activity may prevent age related loss of muscle mass in the lower leg muscles. In addition, isometric knee flexion strength is positively correlated with the duration of moderate physical activity. The results from the previous studies suggest that ambulatory activity with moderate or vigorous intensities can improve lower leg muscle size and function in older adults.

\section{Short-term training studies Walk training}

A number of studies have reported the effect of walk training on aerobic capacity and body composition; ${ }^{23}$ however, only a few studies have observed the influence of walk training on lower body muscle size and strength. In active young men, a short duration (3 weeks) of regular slow-walk training did not change dynamic leg press strength, isometric knee extension strength, or magnetic resonance imaging measured thigh muscle CSA. ${ }^{14}$ In older women aged $76-78$ years, there was no significant change in computed tomography measured thigh muscle CSA following 18 weeks of walk training. ${ }^{24}$ Similarly, active older men and women did not increase magnetic resonance imaging measured mid-thigh muscle CSA and quadriceps muscle volume after 10 weeks of walk training. ${ }^{15}$ On the other hand, one study reported increases in ultrasound measured muscle thickness following 6 months of walk training in sedentary or mildly to moderate active older adults. ${ }^{25}$ They found that muscle thickness increased significantly for knee flexors and dorsi flexors, but not for the knee extensors or plantar flexors. It is clear that the change in muscle size by walk training may be influenced by initial physical activity 
levels and/or programs (intensity, duration, and frequency). In the previous study reported by Kubo et $\mathrm{al},{ }^{25}$ the numbers of steps increased by $44 \%$ from 7025 steps/day to 9915 steps/day (average walking duration was 45 minutes/day, and frequency was 5.4 days/week) although the authors did not report the intensity. These results suggest a possibility that site specific locomotor muscles, which are unable to be differentiated from whole muscle thigh or lower leg measurements, increase following walk training when the volume of walking is significantly increased from baseline.

With regard to muscle strength, several studies have observed increases in strength following walk training in older adults. A study reported that moderate intensity (about $50 \%$ of $\mathrm{VO}_{2}$ max) continuous (8000 steps or more per day) walking increased isometric knee extension (7\%) strength in older men and women. ${ }^{26}$ Furthermore, high intensity interval walking $(>5$ sets of 3 minutes walking at approximately $40 \%$ of $\mathrm{VO}_{2}$ max followed by 3 minutes of walking at $\left.>70 \% \mathrm{VO}_{2} \max \right)$ produced improvements in isometric knee extension (13\%) and flexion (16\%) strength. ${ }^{26}$ On the other hand, following walk training at $45 \%$ of the heart rate reserve in older men and women, there was no change in ether isometric knee extension or flexion strength. ${ }^{15}$ Thus, it appears that the magnitude of improvement of the muscle strength may be associated with exercise intensity during walking. Participants with a low initial fitness level have a greater potential for improving muscle strength and muscle hypertrophy following brisk walk training.

To illustrate this, a study reported that maximum isokinetic knee extension and flexion strength increased by $10 \%$ following 3 months of home based walk training (30-45 minutes, 3-4 sessions per week) in patients with chronic heart failure. ${ }^{27}$ Similarly, patients with peripheral arterial disease performed supervised treadmill walking training ( 3 sessions per week, 12 weeks) and a significant increase in isokinetic plantar flexion strength is observed. ${ }^{28}$

\section{Running training}

Several studies have investigated the effect of chronic running on muscle fiber size, fat free mass, and muscle strength in young and middle-aged subjects. For instance, Dolezal and Potteiger ${ }^{29}$ have shown that 20-45 minutes of running at $65 \%-85 \%$ of the maximum heart rate for 10 weeks did not increase 1RM strength for squat or fat free mass in young men. Additionally, Glowacki et $\mathrm{al}^{30}$ reported that 12 weeks of running significantly increased 1RM strength for leg press and isokinetic knee extension, but it did not change fat free mass. Additionally, in other studies, fat free mass also did not change with running. ${ }^{31,32}$ Thus, it appears that chronic running does not induce an increase in fat free mass for young subjects, although lower limb strength may improve in some cases. Meanwhile, Trappe et $\mathrm{al}^{33}$ have investigated the effects of 16 weeks of marathon training $(\sim 60 \mathrm{~km}$ per week) on muscle fiber size for three leg muscles in young subjects (four men and three women). The authors reported that type 1 and type 2A fiber size in the gastrocnemius muscle was significantly reduced by approximately $20 \%$ following training. ${ }^{33}$ Furthermore, the type 1 and type $2 \mathrm{~A}$ fiber size for the soleus muscle and type 2A fiber size for the vastus lateralis (VL) muscle did not change after the marathon training. The type 1 fibers of the VL were the only fibers that significantly increased in size from marathon training. The authors stated that muscle fiber size in the soleus did not increase by marathon training because the "untrained" soleus has simply adapted to normal daily activity and is in a more conditioned state compared with the VL. ${ }^{34}$ In contrast, other studies have observed that muscle fiber CSA in the VL did not change significantly after chronic running. ${ }^{32,35-37}$ Thus, it is generally observed that chronic running does not induce leg muscle hypertrophy, especially in the thigh muscle, in young and middle-aged adults. However, there are no investigations about the effects of running on leg muscle morphology in older subjects. Interestingly, a previous study reported that a single bout of aerobic exercise enhanced the anabolic response to insulin (sensitivity of feeding) by stimulating mixed muscle protein synthesis and producing a positive protein balance in older adults. ${ }^{38}$ Therefore, it is still a possibility that training induced muscle hypertrophy from running occurs in older men and women with insulin resistance. It should be stated, however, that although mixed muscle protein synthesis often serves as a surrogate marker for myofibrillar protein synthesis, differential responses have been observed within each subfraction. ${ }^{11}$ Therefore, it may be appropriate to measure the individual synthesis rates of myofibrillar, mitochondrial, and sarcoplasmic proteins to better to clarify these issues.

Differences between the effects of run training and walk training on muscle morphology are unclear, but several possibilities exist. Hikida et $\mathrm{al}^{39}$ investigated the ultrastructural changes in the gastrocnemius muscles before and immediately after a marathon event, and found marathon race induced muscle necrosis and also regular distance training induced muscle necrosis. The authors suggest that the initial trauma is probably the disruption of the sarcolemma, which results in an ionic imbalance, especially of calcium. ${ }^{40}$ The increase in calcium concentration activates a protease 
and breaks down the Z-lines and thin filaments. ${ }^{41} \mathrm{~A}$ recent study showed that calcium concentrations in the VL muscles increased immediately after a $10 \mathrm{~km}$ and a $20 \mathrm{~km}$ run, and the calcium accumulation was positively related to running distance and time spent running. ${ }^{42}$ Interestingly, the authors also found that the calcium response to a $10 \mathrm{~km}$ run did not significantly alter following 10 weeks of run training (distance of $\sim 29 \mathrm{~km}$ per week, three times/week). It could be speculated, therefore, that repeated distance running, but not walking, caused some damage that would make it harder to recover from the damaging exercise bout. ${ }^{43}$ This insufficient recovery may ultimately affect the capability of the muscle to grow.

Although it appears that chronic continuous running does not increase fat free mass and muscle fiber size, Krustrup et $a l^{36}$ have investigated the effect of 1 hour of running versus recreational soccer training at the same exercise time and intensity on muscle fiber size in untrained men aged 20-43 years, and reported that only soccer training ( 1 hour per day and 2.3 days per week) significantly increased muscle fiber CSA in VL (15\%), fat free mass (3\%), and maximal isometric knee extension strength (11\%). For untrained women aged 19-42 years, similar soccer training (1 hour per day for 1.8 days per week) demonstrated significantly increased lean mass of the leg $(11 \%)$, and they tended to exhibit increased muscle fiber CSA in VL $(P=0.09) .{ }^{37}$ These data suggest that soccer training (intermittent jogging/ running) at various intensities and motions (including lateral movements) has the potential to promote muscle hypertrophy and strength gain. The mechanism of muscle hypertrophy is unclear, although it may be possible that the higher elevation in blood lactate during soccer exercise compared to continuous running indirectly affect increases in muscle fiber size induced by recreational soccer training. ${ }^{36}$ Recently, Inaba et $\mathrm{al}^{44}$ reported the biomechanical factors contributing to quickness in lateral movements and found that extension torques of the hip, knee, and ankle joints contribute substantially to the changes in side step distances. The lateral movement and quickness during soccer exercise may be a crucial factor for muscle hypertrophy in the leg muscles, especially in the quadriceps muscle. However, further studies are needed to elucidate whether intermittent running can induce hypertrophy at the whole muscle level.

\section{Relatively long-term training studies}

Most intervention studies on running have been relatively short-term (less than or equal to 10 weeks), but some studies have performed walking and jogging for over half a year.
Schwartz et al ${ }^{45}$ have shown that walking and jogging, 5 days per week for 27 weeks, did not change thigh muscle CSA in young men, but significantly increased thigh muscle CSA ( $9 \%$ ) for older men. As previously mentioned, 4 months of running reduced type 1 and type 2 A fiber size (20\%) of the gastrocnemius muscle for young men and women, ${ }^{31}$ but Coggan et a ${ }^{46}$ have demonstrated that walking and jogging, 4 days per week for 9-12 months, significantly increased (6\%-18\%) type 1 and type $2 \mathrm{~A}$ fiber size of the gastrocnemius muscle in older men and women. Thus, walking or jogging/running from several weeks to 2-3 months rarely induces muscle hypertrophy, but it is possible that relatively long periods of training for over half a year can increase leg muscle size by approximately $1 \%$ per month for older adults. Further studies are required to make a final decision because only a few studies have reported that walking and/or jogging increased muscle size.

\section{Influence of specific environment Hypobaric hypoxia}

The specific internal environment in the legs during walking and jogging/running can also influence the muscle hypertrophy and strength response. For instance, high altitude mediated hypobaric hypoxia creates many morphological and physiological changes. A study reported that thigh muscle CSA decreased by $10 \%$ after sojourn at a high altitude (Himalayas; greater than $5000 \mathrm{~m}$ for over 56 days), although whether a change in physical activity occurred is not clear. In that study, the loss of thigh muscle size is mainly due to a decrease in myofibrillar proteins. ${ }^{47}$ Mizuno et $\mathrm{a}^{48}$ also reported that muscle fiber size decreased by an average of $15 \%$ in the $\mathrm{VL}$ and biceps brachii muscles in both active and less active men after 75 days of altitude (greater than $5250 \mathrm{~m}$ ) exposure. Other studies investigated the effects of acute and chronic hypobaric hypoxia and physical exercise on muscle protein metabolism, and the results suggest that the large increase in protein degradation is the underlying mechanism for the loss of skeletal muscle mass. ${ }^{49,50}$ Contrary to chronic hypobaric hypoxia, a recent study investigated the effects of intermittent systemic hypoxia on high intensity (70\% 1RM) resistance training induced muscle hypertrophy in young men. ${ }^{51}$ The researchers found that muscle hypertrophic responses are greater in resistance exercise under hypoxia than those of a normoxia condition. However, Friedmann et al ${ }^{52}$ reported that resistance training with low intensity ( $30 \% 1 \mathrm{RM})$ under hypoxia did not promote muscle hypertrophy. These findings suggest that exercise training under intermittent hypoxia cannot lead to muscle hypertrophy with low workloads such as walking and jogging. 
Table I Summary of the effects of ambulation on muscle size and strength in older adults

\begin{tabular}{llll}
\hline & \multicolumn{2}{l}{ Study types } & \\
\cline { 2 - 4 } & $\begin{array}{l}\text { Short-term } \\
(\leq 6 \text { months) }\end{array}$ & $\begin{array}{l}\text { Long-term } \\
\text { (>6 months) }\end{array}$ & Daily PA* \\
\hline Brisk walking & + & + & ++ \\
Running & NS (maybe $)$ & NS (maybe $)$ & NS \\
Intermittent running & + & NS & NS \\
Specific environment & & \\
Hypobaric hypoxia & $\sim$ & NS & NS \\
Blood flow restriction & ++ & NS & NS
\end{tabular}

Notes: No effect $(\sim)$; somewhat effective $(+)$; effective $(++)$; very effective $(+++)$;

*Accelerometer-determined physical activity.

Abbreviations: PA, physical activity; NS, no study.

\section{Blood flow restriction}

As stated previously, the potential for walk training induced muscle hypertrophy is weak and may be specific to active locomotor muscles. Interestingly, when combined with BFR to the exercising muscles, walk training induced muscle hypertrophy in the lower limb muscles has been observed in both young and older adults. An earlier study has shown that twice daily walk training with BFR at $50 \mathrm{~m} /$ minute for 10 minutes of actual walking, 6 days per week for 3 weeks, increased quadriceps muscle volume (4\%) and isometric knee extension strength (10\%) in young men. ${ }^{14}$ Additionally, Park et $\mathrm{al}^{53}$ reported an increase in muscle strength following 2 weeks of twice daily BFR walk training in young athletes. ${ }^{53}$ In older adults, 10 weeks of BFR walk training can lead to significant improvements in thigh muscle CSA/volume and knee joint strength. ${ }^{15}$ Recently, a study has reported that muscle volume of the thigh and lower leg increased by $4 \%$ and $3 \%$, respectively, in the BFR walk group following training $;{ }^{54}$ however, gluteus maximus muscle volume and the lumbar L4-L5 muscle CSA did not change in the BFR walk group, although there was a trend $(P=0.07)$ for an increase in iliopsoas muscle volume. Therefore, the combination of leg muscle BFR with slow-walk training elicits muscle hypertrophy only in the blood flow restricted leg muscles, which might be due to an accumulation of metabolites within the muscle fiber and subsequent muscle cell swelling induced from the application of BFR. ${ }^{55,56}$

\section{Conclusion}

It is an undeniable fact that brisk walking and jogging are potent stimuli for improving maximal oxygen uptake $\left(\mathrm{VO}_{2} \max \right)$ in older men and women. This improvement in cardiorespiratory fitness may also be associated with increases in muscle size and strength depending on the intensity, duration, and environment in which walking and jogging/running are performed. Table 1 shows a summary of the effects of ambulation on muscle size and strength in older adults. Daily ambulatory activity with moderate ( $>3$ METs) intensity, estimated by accelerometer, is positively correlated with lower body muscle size and function in older adults. Although the effects of short-term training are uncertain, it is possible that relatively long periods of walking, jogging, and/or intermittent running training for over half a year can increase leg muscle size in older adults. In addition, slow-walk training in a combination with leg muscle BFR elicits muscle hypertrophy only in the blood flow restricted leg muscles. Competitive marathon running and regular high intensity distance running in young and middle-aged adults may not produce leg muscle hypertrophy due to insufficient recovery from the damaging running bout, although there is no study investigating the effects of running on leg muscle morphology in older subjects. It is clear that skeletal muscle hypertrophy can occur independently of exercise mode and its load.

\section{Disclosure}

The authors report no conflicts of interest in this work. None of the authors had financial or personal conflict of interests with regard to this study.

\section{References}

1. Pollock ML, Dimmick J, Miller HS Jr, Kendrick Z, Linnerud AC. Effects of mode of training on cardiovascular function and body composition of adult men. Med Sci Sports. 1975;7(2):139-145.

2. Murphy MH, Hardman AE. Training effects of short and long bouts of brisk walking in sedentary women. Med Sci Sports Exerc. 1998;30(1):152-157.

3. Laukkanen RM, Kukkonen-Harjula TK, Oja P, Pasanen ME, Vuori IM. Prediction of change in maximal aerobic power by the $2-\mathrm{km}$ walk test after walking training in middle-aged adults. Int J Sports Med. 2000;21(2):113-116

4. Saltin B, Astrand PO. Maximal oxygen uptake in athletes. J Appl Physiol. 1967;23(3):353-358

5. Brisswalter J, Fougeron B, Legros P. Variability in energy cost and walking gait during race walking in competitive race walkers. $\mathrm{Med} \mathrm{Sci}$ Sports Exerc. 1998;30(9):1451-1455

6. Costill DL, Daniels J, Evans W, Fink W, Krahenbuhl G, Saltin B. Skeletal muscle enzymes and fiber composition in male and female track athletes. J Appl Physiol. 1976;40(2):149-154.

7. Harber M, Trappe S. Single muscle fiber contractile properties of young competitive distance runners. J Appl Physiol. 2008;105(2):629-636.

8. Gollnick PD, Armstrong RB, Saubert CW 4th, Piehl K, Saltin B. Enzyme activity and fiber composition in skeletal muscle of untrained and trained men. J Appl Physiol. 1972;33(3):312-319.

9. Garber CE, Blissmer B, Deschenes MR, et al; for American College of Sports Medicine. American College of Sports Medicine position stand. Quantity and quality of exercise for developing and maintaining cardiorespiratory, musculoskeletal, and neuromotor fitness in apparently healthy adults: guidance for prescribing exercise. Med Sci Sports Exerc 2011;43(7):1334-1359. 
10. Kumar V, Selby A, Rankin D, et al. Age-related differences in the dose-response relationship of muscle protein synthesis to resistance exercise in young and old men. $J$ Physiol. 2009;587(Pt 1):211-217.

11. Burd NA, West DW, Staples AW, et al. Low-load high volume resistance exercise stimulates muscle protein synthesis more than high-load low volume resistance exercise in young men. PLoS One. 2010;5(8):e12033.

12. Mitchell CJ, Churchward-Venne TA, West DW, et al. Resistance exercise load does not determine training-mediated hypertrophic gains in young men. J Appl Physiol. 2012;113(1):71-77.

13. Ogasawara R, Loenneke JP, Thiebaud RS, Abe T. Low-load bench press training to fatigue results in muscle hypertrophy similar to high-load bench press training. Int J Clin Med. 2013;4:114-121.

14. Abe T, Kearns CF, Sato Y. Muscle size and strength are increased following walk training with restricted venous blood flow from the leg muscle, Kaatsu-walk training. J Appl Physiol. 2006;100(5):1460-1466.

15. Ozaki H, Sakamaki M, Yasuda T, et al. Increases in thigh muscle volume and strength by walk training with leg blood flow reduction in older participants. J Gerontol A Biol Sci Med Sci. 2011;66(3):257-263.

16. Harber MP, Konopka AR, Douglass MD, et al. Aerobic exercise training improves whole muscle and single myofiber size and function in older women. Am J Physiol Regul Integr Comp Physiol. 2009;297(5): R1452-R1459.

17. Sawai S, Sanematsu H, Kanehisa H, Tsunoda N, Tetsuo F. Sexual-related difference in the level of muscular activity of trunk and lower limb during basic daily life action. Japanese Journal of Physical Fitness and Sports Medicine. 2006;55(2):247-257. Japanese.

18. Wall-Scheffler CM, Chumanov E, Steudel-Numbers K, Heiderscheit B. Electromyography activity across gait and incline: The impact of muscular activity on human morphology. Am J Phys Anthropol. 2010; 143(4):601-611.

19. Bassey EJ, Bendall MJ, Pearson M. Muscle strength in the triceps surae and objectively measured customary walking activity in men and women over 65 years of age. Clin Sci (Lond). 1988;74(1):85-89.

20. Scott D, Blizzard L, Fell J, Jones G. Ambulatory activity, body composition, and lower-limb muscle strength in older adults. Med Sci Sports Exerc. 2009;41(2):383-389.

21. Park H, Park S, Shephard RJ, Aoyagi Y. Yearlong physical activity and sarcopenia in older adults: the Nakanojo Study. Eur JAppl Physiol. 2010; 109(5):953-961.

22. Abe T, Mitsukawa N, Thiebaud RS, Loenneke JP, Loftin M, Ogawa M. Lower body site-specific sarcopenia and accelerometer-determined moderate and vigorous physical activity: the HIREGASAKI study. Aging Clin Exp Res. Epub November 26, 2012.

23. Murphy MH, Nevill AM, Murtagh EM, Holder RL. The effect of walking on fitness, fatness and resting blood pressure: a meta-analysis of randomized, controlled trials. Prev Med. 2007;44(5):377-385.

24. Sipilä S, Suominen H. Effects of strength and endurance training on thigh and leg muscle mass and composition in elderly women. $J \mathrm{Appl}$ Physiol. 1995;78(1):334-340.

25. Kubo K, Ishida Y, Suzuki S, et al. Effects of 6 months of walking training on lower limb muscle and tendon in elderly. Scand J Med Sci Sports. 2008;18(1):31-39.

26. Nemoto K, Gen-no H, Masuki S, Okazaki K, Nose H. Effects of highintensity interval walking training on physical fitness and blood pressure in middle-aged and older people. Mayo Clin Proc. 2007;82(7):803-811.

27. Servantes DM, Pelcerman A, Salvetti XM, et al. Effects of home-based exercise training for patients with chronic heart failure and sleep apnoea: a randomized comparison of two different programs. Clin Rehabil. 2012;26(1):45-57.

28. Wang J, Zhou S, Bronks R, Graham J, Myers S. Effects of supervised treadmill-walking training on strength and endurance of the calf muscles of individuals with peripheral arterial disease. Clin J Sports Med. 2006;16(5):397-400.

29. Dolezal BA, Potteiger JA. Concurrent resistance and endurance training influence basal metabolic rate in nondieting individuals. J Appl Physiol. 1998;85(2):695-700.
30. Glowacki SP, Martin SE, Maurer A, Baek W, Green JS, Crouse SF. Effects of resistance, endurance, and concurrent exercise on training outcomes in men. Med Sci Sports Exerc. 2004;36(12):2119-2127.

31. Craig BW, Lucas J, Pohlman R, Stelling H. The effects of running, weightlifting and a combination of both on growth hormone release. Journal of Strength and Conditioning Research. 1991;5(4): 198-203.

32. Suter E, Hoppeler H, Claassen H, et al. Ultrastructural modification of human skeletal muscle tissue with 6-month moderate-intensity exercise training. Int J Sports Med. 1995;16(3):160-166.

33. Trappe S, Harber M, Creer A, et al. Single muscle fiber adaptations with marathon training. J Appl Physiol. 2006;101(3):721-727.

34. Luden N, Hayes E, Minchev K, et al. Skeletal muscle plasticity with marathon training in novice runners. Scand J Med Sci Sports. 2011;22(5):662-670.

35. Ingjer F. Effects of endurance training on muscle fibre ATP-ase activity, capillary supply and mitochondrial content in man. J Physiol. 1979;294:419-432.

36. Krustrup P, Christensen JF, Randers MB, et al. Muscle adaptations and performance enhancements of soccer training for untrained men. Eur J Appl Physiol. 2010;108(6):1247-1258.

37. Bangsbo J, Nielsen JJ, Mohr M, et al. Performance enhancements and muscular adaptations of a 16-week recreational football intervention for untrained women. Scand J Med Sci Sports. 2010;20 Suppl 1:24-30.

38. Fujita S, Rasmussen BB, Cadenas JG, et al. Aerobic exercise overcomes the age-related insulin resistance of muscle protein metabolism by improving endothelial function and Akt/mammalian target of rapamycin signaling. Diabetes. 2007;56(6):1615-1622.

39. Hikida RS, Staron RS, Hagerman FC, Sherman WM, Costill DL. Muscle fiber necrosis associated with human marathon runners. J Neurol Sci. 1983;59(2):185-203.

40. Busch WA, Stromer MH, Goll DE, Suzuki A. Ca2+-specific removal of Z lines from rabbit skeletal muscle. J Cell Biol. 1972;52(2):367-381.

41. Hikida RS. Z-line extraction: comparative effects in avian skeletal muscle fiber types. J Ultrastruct Res. 1978;65(3):266-278.

42. Overgaard K, Fredsted A, Hyldal A, Ingemann-Hansen T, Gissel H, Clausen T. Effects of running distance and training on $\mathrm{Ca} 2+$ content and damage in human muscle. Med Sci Sports Exerc. 2004; 36(5):821-829

43. Warhol MJ, Siegel AJ, Evans WJ, Silverman LM. Skeletal muscle injury and repair in marathon runners after competition. Am J Pathol. 1985;118(2):331-339.

44. Inaba Y, Yoshioka S, Iida Y, Hay DC, Fukashiro S. A biomechanical study of side steps at different distances. J Appl Biomech. Epub August 22, 2012.

45. Schwartz RS, Shuman WP, Larson V, et al. The effect of intensive endurance exercise training on body fat distribution in young and older men. Metabolism. 1991;40(5):545-551.

46. Coggan AR, Spina RJ, King DS, et al. Skeletal muscle adaptations to endurance training in 60- to 70-yr-old men and women. J Appl Physiol. 1992;72(5):1780-1786.

47. Hoppeler H, Kleinert E, Schlegel C, et al. Morphological adaptations of human skeletal muscle to chronic hypoxia. Int J Sports Med. 1990; 11 Suppl 1:S3-S9.

48. Mizuno M, Savard GK, Areskog NH, Lundby C, Saltin B. Skeletal muscle adaptations to prolonged exposure to extreme altitude: a role of physical activity? High Alt Med Biol. 2008;9(4):311-317.

49. Imoberdorf R, Garlick PJ, McNurlan MA, et al. Skeletal muscle protein synthesis after active or passive ascent to high altitude. Med Sci Sports Exerc. 2006;38(6):1082-1087.

50. Chaudhary P, Suryakumar G, Prasad R, Singh SN, Ali S, Ilavazhagan G. Chronic hypobaric hypoxia mediated skeletal muscle atrophy: role of ubiquitin-proteasome pathway and calpains. Mol Cell Biochem. 2012;364(1-2):101-113.

51. Nishimura A, Sugita M, Kato K, Fukuda A, Sudo A, Uchida A. Hypoxia increases muscle hypertrophy induced by resistance training. Int J Sports Physiol Perform. 2010;5(4):497-508. 
52. Friedmann B, Kinscherf R, Borisch S, Richter G, Bärtsch P, Billeter R. Effects of low-resistance/high-repetition strength training in hypoxia on muscle structure and gene expression. Pflugers Arch. 2003;446(6):742-751.

53. Park S, Kim JK, Choi HM, Kim HG, Beekley MD, Nho H. Increase in maximal oxygen uptake following 2-week walk training with blood flow occlusion in athletes. Eur J Appl Physiol. 2010;109(4):591-600.

54. Sakamaki M, Bemben MG, Abe T. Legs and trunk muscle hypertrophy following walk training with restricted leg muscle blood flow. J Sports Sci Med. 2011;10:338-340.
55. Abe T, Loenneke JP, Fahs CA, Rossow LM, Thiebaud RS, Bemben MG. Exercise intensity and muscle hypertrophy in blood flow-restricted limbs and non-restricted muscles: a brief review. Clin Physiol Funct Imaging. 2012;32(4):247-252.

56. Loenneke JP, Fahs CA, Rossow LM, Abe T, Bemben MG. The anabolic benefits of venous blood flow restriction training may be induced by muscle cell swelling. Med Hypotheses. 2012;78(1):151-154.

\section{Publish your work in this journal}

Clinical Interventions in Aging is an international, peer-reviewed journal focusing on evidence-based reports on the value or lack thereof of treatments intended to prevent or delay the onset of maladaptive correlates of aging in human beings. This journal is indexed on PubMed Central, MedLine, the American Chemical Society's 'Chemical Abstracts

\section{Dovepress}

Service' (CAS), Scopus and the Elsevier Bibliographic databases. The manuscript management system is completely online and includes a very quick and fair peer-review system, which is all easy to use. Visit http://www.dovepress.com/testimonials.php to read real quotes from published authors.

Submit your manuscript here: http://www.dovepress.com/clinical-interventions-in-aging-journal 